\title{
Genetic influences on splenic function in coeliac disease
}

\author{
J G O'GRADY, F M STEVENS, AND C F MCCARTHY \\ From the Department of Medicine, University College and Regional Hospital, Galway, Ireland
}

SUMmARY Splenic function was assessed using 'pitted' erythrocyte counts in 61 first degree relatives of patients with coeliac disease. 'Pitted' erythrocyte counts were normal in 12 parents, but were raised in $20 \%$ of 49 siblings and/or children of coeliac patients. First degree relatives had higher 'pitted' erythrocyte counts than normal controls $(p=0.002)$. The counts were lower in coeliac relatives than in age matched coeliacs $(p=0.0001)$, but no difference was present between the relatives and coeliac patients whose small bowel mucosa was morphologically normal. Considerable interfamily variation was found in 'pitted' erythrocyte counts, both in the coeliac patients and first degree relatives, and the pattern tended to 'run true' within families. The genetic factor influencing splenic function in coeliac disease is not HLA-linked but seems to be associated with a second, probably recessive, gene influencing the inheritance of coeliac disease.

Genetic determinants have been proposed as a factor contributing to hyposplenism in coeliac disease, ${ }^{1}$ but the HLA-B8 and DR3 antigens do not appear to influence splenic function in these patients. ${ }^{2}$ The presence of these antigens in the vast majority of patients with coeliac disease, however, makes it difficult to exclude HLA-linked genetic factors from playing a role in the causation of hyposplenism. ${ }^{2}$ In addition there is strong evidence to suggest the presence of a second gene influencing the inheritance of coeliac disease..$^{3-5}$ We have used 'pitted' erythrocyte counts to assess splenic function in families and first degree relatives of patients with coeliac disease, with particular regard to genetic influences.

\section{Methods}

\section{SUBJECTS}

'Pitted' erythrocyte counts were carried out by a single blinded observer as previously described, ${ }^{2}$ on 61 first degree relatives of patients with coeliac disease. These consisted of 12 parents, 23 children, 20 siblings and six subjects who were both siblings and children of index cases. Forty six of the first degree relatives were from nine families, involving 19 index cases. The small bowel mucosa was morphologically normal in the seven parents who

Address for correspondence: Prof C F McCarthy, Department of Medicine. Regional Hospital, Galway, Ireland.

Received for publication 15 November 1984. were biopsied. All of the remaining relatives had small bowel biopsies which were morphologically normal while on gluten containing diets, and none had any clinical, haematological, or biochemical evidence of coeliac disease. The siblings and children consisted of 28 females and 21 males with an age range of 1.5 to 30 years. The diagnosis of coeliac disease was based on the demonstration of the typical small bowel mucosal lesion followed by histological improvement after withdrawal of gluten from the diet. Control groups for the first degree relatives (excluding parents) consisted of 26 normal subjects, 19 splenectomised subjects and 47 patients with coeliac disease. These age-matched control groups were subsets of larger study groups described elsewhere. ${ }^{2}$ The normal controls and coeliac patients were appropriately sex-matched, but this was not possible with the splenectomised subjects who had a considerable male predominance $(M / F=16 / 3)$.

HLA-typing was done using the standard microlymphocyto-toxicity technique. The Mann Whitney$\mathrm{U}$ test was used for statistical analysis.

\section{Results}

'Pitted' erythrocyte counts in coeliac patients and their relatives were classified as raised if they exceeded the upper limit of the range found in age-matched normal controls $(7 \cdot 0 \%-7 \cdot 5 \%)$, as described in detail elsewhere. ${ }^{2}$ All 12 parents had 'pitted' erythrocyte counts that were in the normal range, but raised counts were found in three siblings 
$(15 \%)$, six children $(26 \%)$ and in one sibling/child $(16.6 \%)$. The mean $( \pm \mathrm{SD})$ 'pitted' erythrocyte counts for the siblings $(4.2 \% \pm 3.2 \%)$, children $(5.4 \% \pm 2.4 \%)$ and siblings/children $(3.9 \% \pm 2.8 \%)$ did not differ significantly and the mean for the overall group was $4 \cdot 5 \% \pm 2 \cdot 8 \%$. This was significantly higher than the normal controls $(2.6 \% \pm 1.6 \%$; $\mathrm{p}=0.002$ ) (Fig. 1). The counts in the coeliac relatives were lower than in the combined age-matched coeliac patients $(7 \cdot 3 \% \pm 3.6 \% ; p=0.0001)$, but no difference was present between the relatives and 17 coeliacs who were on gluten free diets and whose small bowel biopsies were morphologically normal at the time of study $(5.5 \% \pm 1.8 \%$; NS). The 'pitted' erythrocyte counts were higher in the splenectomised subjects than in all other study groups $(\mathrm{p}=0.0001)$.

The HLA-B8 antigen was present in $58.5 \%$ of the coeliac relatives $(n=41), 17.4 \%$ of the normal controls $(n=23), 42.8 \%$ of the splenectomised controls $(n=14)$ and $83.6 \%$ of the coeliac patients $(n=47)$. No difference was found in 'pitted' erythrocyte counts between HLA-B8 positive and negative subjects in any of the study groups.

Of the nine families studied in detail, four had a

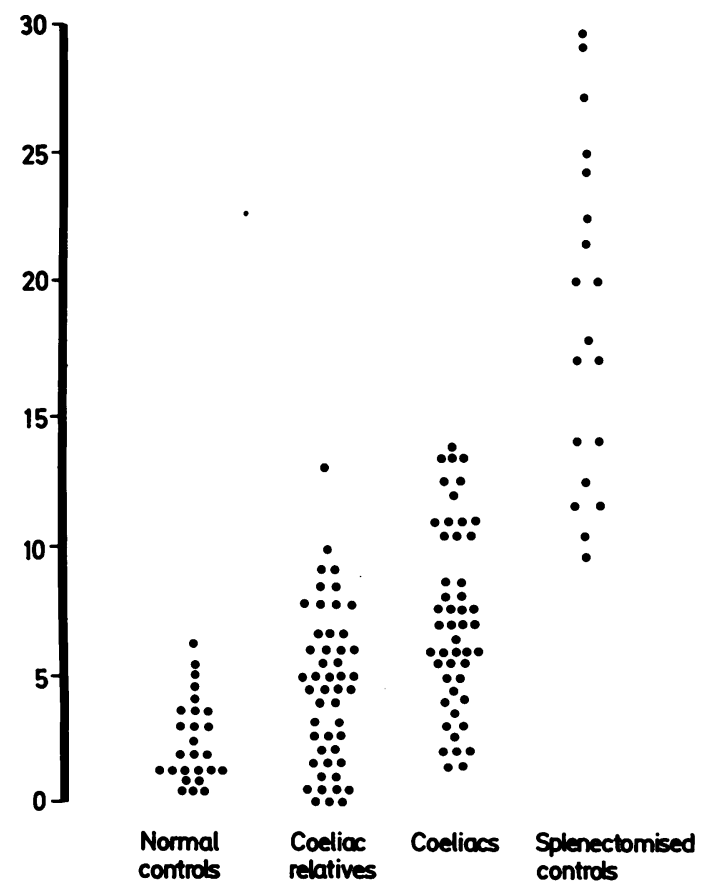

Fig. 1 'Pitted' erythrocyte counts (\%) in coeliac relatives, coeliac patients, normal and splenectomised controls (all under the age of 30 years). single index coeliac (parent in two, sibling in two,), two had both a parent and a sibling as index cases and in the remaining three multiple siblings were the index cases. Raised 'pitted' erythrocyte counts were found in the index coeliacs in six of the nine families (Fig. 2). In the three families (1-3) where the 'pitted' erythrocyte counts were normal in the index cases, the counts were also low in the unaffected relatives. The HLA-B8 antigen was present in two of these families. Families 4-6 had one parent each with coeliac disease and raised 'pitted' erythrocyte count. Two of these families contained children who did not have coeliac disease but had raised 'pitted' erythrocyte counts. The coeliac parent in both these families had the HLA-B8 antigen, but this was not inherited by any of the children with raised counts. The only coeliac child in families 4-6 did inherit the HLA-B8 antigen and had a raised 'pitted' erythrocyte count. Families 7-9 contained multiple siblings with coeliac disease, but only one of these coeliacs was studied in family 8 , and the parents were not studied in families 7 and 9 . The 'pitted' erythrocyte counts were raised in both the coeliacs in family 7 and in five of the six coeliacs in family 9. Two unaffected siblings in families 7-9 had raised 'pitted' erythrocyte counts and both of these shared the HLA-B8 antigen with their coeliac siblings.

\section{Discussion}

'Pitted' erythrocyte counts are a simple and accurate method of assessing splenic function and, in patients with coeliac disease, they have been found to correlate with the clearance of radioactively labelled, heat damaged erythrocytes from the circulation. ${ }^{6}$ They are especially useful when studying large numbers and when exposure to radioactivity is undesirable. The findings of this study support the suggestion of Trewby et $a l^{1}$ that genetic determinants play a role in the pathogenesis of the hyposplenism of coeliac disease. We have previously shown that about $80 \%$ of adult coeliac patients are susceptible to hyposplenism and that $20 \%$ of coeliacs do not develop impaired splenic function, even after long periods of exposure to dietary gluten. ${ }^{2}$ This present study shows that the presence or absence of hyposplenism in patients with coeliac disease 'runs true' in different families. In addition $20 \%$ of first degree relatives of patients with coeliac disease showed evidence of hyposplenism and this also followed a familial pattern. In this study hyposplenism was only found in first degree relatives if the index case(s) showed susceptibility to hyposplenism. Extended studies, however, are required to confirm this finding. The converse is not true, as splenic function was frequently normal in 


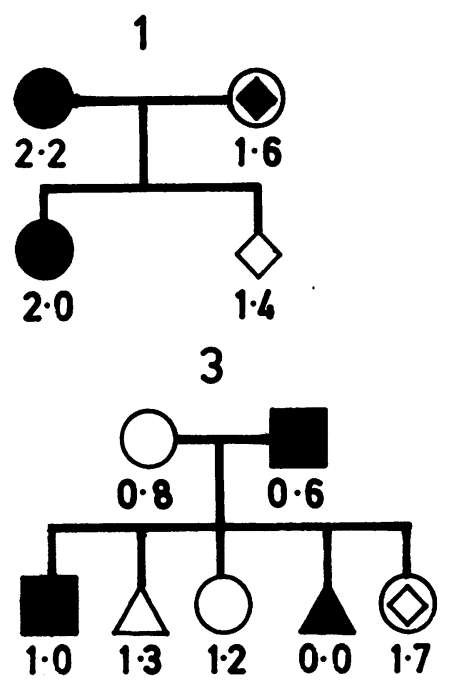

5
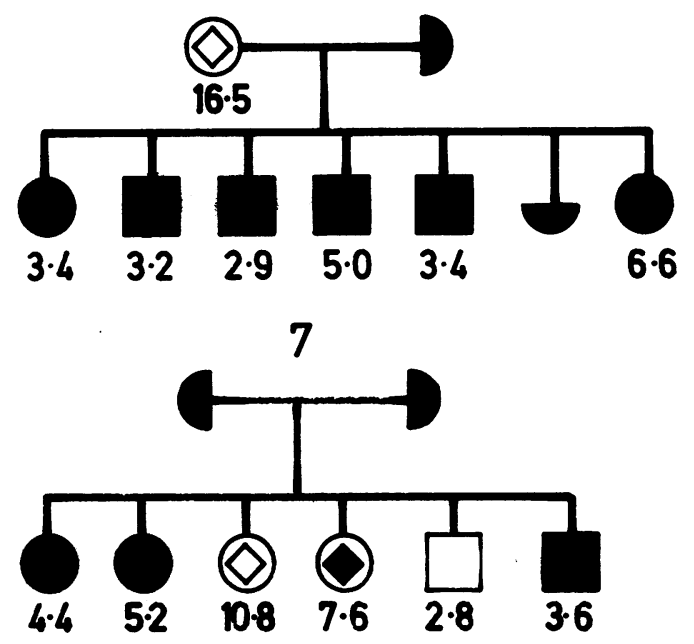
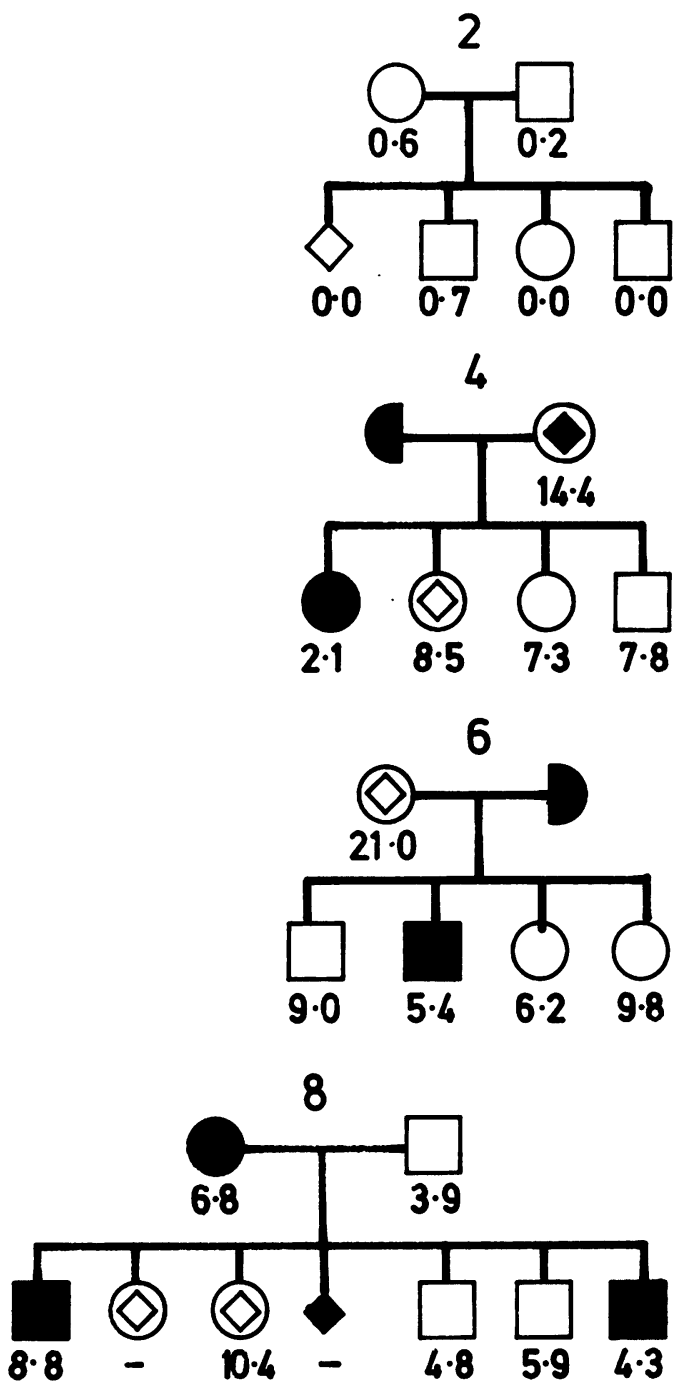

9

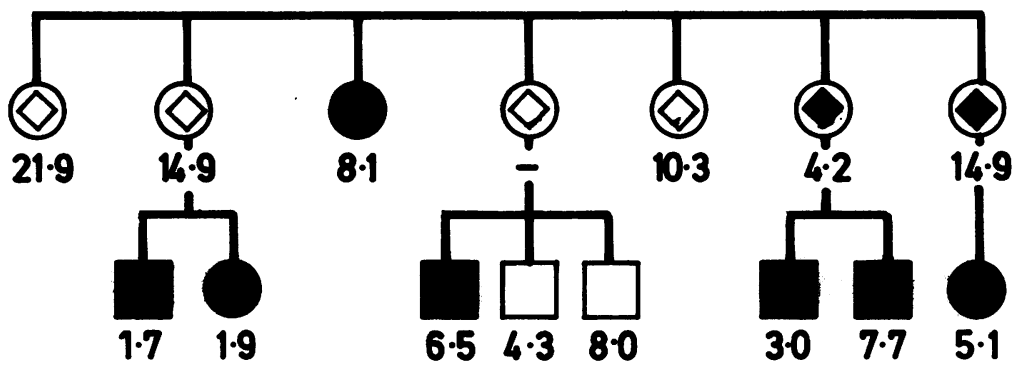

Fig. 2 Family trees with 'pitted' erythrocyte counts for each member. $\downarrow=$ male coeliac; $\downarrow=$ female coeliac; when encircled $=H L A-B 8$ positive. The unaffected relatives are indicated as follows: $O=$ male $H L A-B 8$ positive: $O=$ male $H L A-B 8$ negative; $\square=$ female $H L A-B 8$ positive; $\square=$ female $H L A-B 8$ negative. Family members studied but who did not have a small bowel $=\triangle ;$ family members not studied $=\mathbf{D}$. 
first degree relatives of hyposplenic coeliacs.

A two locus model for the inheritance of coeliac disease, with each gene being recessively inherited, has been proposed. ${ }^{3}$ One of these genes is linked to the HLA-B8 and the DR3 antigens. We have previously shown that the HLA-B8 and DR3 antigens do not influence 'pitted' erythrocyte counts in coeliac disease. ${ }^{2}$ These family studies also show that hyposplenism in coeliac disease is independent of the HLA-B8 antigen and presumably the associated gene coding for coeliac disease. The second gene involved in the inheritance of coeliac disease is probably related to the Gm-locus and this may be the gene influencing splenic function. The proposed recessive nature of this gene is in keeping with the normal 'pitted' erythrocyte counts in the unaffected parents. It is interesting that hyposplenism was found in non-coeliac children of coeliac patients only if they did not inherit the HLA-B8 antigen from their coeliac parent. This could reflect a situation where the children are homozygous for the $\mathrm{Gm}$ associated gene and thus susceptible to hyposplenism, but do not have the HLA associated gene and consequently do not develop clinical coeliac disease. The significance of this combination is unknown, but it is interesting that the coeliac relatives had 'pitted' erythrocyte counts similar to age-matched coeliacs whose small bowel biopsies had returned to normal. This supports the suggestion that genetic predisposition coupled with an as yet unidentified factor associated with damaged small bowel mucosal, cause the hyposplenism of coeliac diasese.

We are very grateful to the Medical Research Council of Ireland for financial support. A preliminary report was delivered to the British Society of Gastroenterology (September 1982).

\section{References}

1 Trewby PN, Chipping PM, Palmer ST, Roberts PD, Lewis SM, Stewart JS. Splenic function in adult coeliac disease: is it reversible? Gut 1981; 22: 628-32.

2 O'Grady JG, Stevens FM, Harding B, O'Gorman TA, McNicholl B, McCarthy CF. Hyposplenism in glutensensitive enteropathy: Natural history, incidence and relationship to diet and small bowel morphology. Gastroenterology 1984; 87: 1326-31.

3 Greenberg DA, Lange KL. A maximum likelihood test of the two-locus model of coeliac disease. Am J Med Genet 1982; 12: 75-82.

4 Kagnoff MF. Two genetic loci control the murine immune response to A-gliadin. Nature 1982; 296: $158-60$

5 Kagnoff MF, Weiss JB, Brown RJ, Lee T, Schanfield MS. Immunoglobulin allotype markers in glutensensitive enteropathy. Lancet 1983; 1: 952-3.

6 Corazza GR, Bullen AW, Hall R, Brown RC, Baxter $P$, Losowsky MS. Simple method of assessing splenic function in adult coeliac disease. Clin Sci 1981; 60: 109-13. 